\title{
Remnants of ancestral larval eyes in an eyeless mollusk? Molecular characterization of photoreceptors in the scaphopod Antalis entalis
}

\author{
Tim Wollesen $^{1^{*}}$, Carmel McDougall ${ }^{2}$ (1) and Detlev Arendt ${ }^{1}$ (1)
}

\begin{abstract}
Background: Eyes have evolved and been lost multiple times during animal evolution, however, the process of eye loss has only been reconstructed in a few cases. Mollusks exhibit eyes as varied as the octopod camera eye or the gastropod cup eye and are ideal systems for studying the evolution of eyes, photoreceptors, and opsins.

Results: Here, we identify genes related to photoreceptor formation and function in an eyeless conchiferan mollusk, the scaphopod Antalis entalis, and investigate their spatial and temporal expression patterns during development. Our study reveals that the scaphopod early mid-stage trochophore larva has putative photoreceptors in a similar location and with a similar gene expression profile as the trochophore of polyplacophoran mollusks. The apical and post-trochal putative photoreceptors appear to co-express go-opsin, six 1/2, myoV, and eya, while expression domains in the posterior foot and pavilion (posterior mantle opening) show co-expression of several other candidate genes but not go-opsin. Sequence analysis reveals that the scaphopod Go-opsin amino acid sequence lacks the functionally important lysine (K296; Schiff base) in the retinal-binding domain, but has not accumulated nonsense mutations and still exhibits the canonical G-protein activation domain.

Conclusions: The scaphopod Go-opsin sequence reported here is the only known example of a bilaterian opsin that lacks lysine K296 in the retinal-binding domain. Although this may render the Go-opsin unable to detect light, the protein may still perform sensory functions. The location, innervation, development, and gene expression profiles of the scaphopod and polyplacophoran apical and post-trochal photoreceptors suggest that they are homologous, even though the scaphopod post-trochal photoreceptors have degenerated. This indicates that post-trochal eyes are not a polyplacophoran apomorphy but likely a molluscan synapomorphy lost in other mollusks. Scaphopod eye degeneration is probably a result of the transition to an infaunal life history and is reflected in the likely functional degeneration of Go-opsin, the loss of photoreceptor shielding pigments, and the scarce expression of genes involved in phototransduction and eye development. Our results emphasize the importance of studying a phylogenetically broad range of taxa to infer the mechanisms and direction of body plan evolution.
\end{abstract}

Keywords: Apical organ, Evolution and development, Gastropod, Lophotrochozoan, Mollusc, Platynereis, Polyplacophora, Retinal-binding domain, Spiralia, Vision

\footnotetext{
*Correspondence: tim.wollesen@embl.de

1 EMBL, Meyerhofstraße 1, 69117 Heidelberg, Germany

Full list of author information is available at the end of the article
} 


\section{Background}

Vision is among the most important sensory modalities for bilaterian animals and it has been suggested that eyes have been independently gained and lost several times [1-4]. Simple cup-shaped eyes composed of photoreceptor cells and shading pigments probably already existed in the last common bilaterian ancestor [5]. Photoreceptor cells possess expanded surface areas to store photopigments (opsins), and while rhabdomeric photoreceptors possess microvilli on their apical surface for this purpose, ciliary photoreceptors possess surface extended cilia [5]. Similar gene expression profiles and comparisons of molecular and morphological characteristics of photoreceptors have shaped inferences of the putative ancestral organization of shared receptor cells [6, 7]. For example, recent studies suggest that the last common bilaterian ancestor possessed several opsins, including a canonical R-opsin, a non-canonical R-opsin, a C-opsin, a Go-opsin, a retinal pigment epithelium-retinal G-protein-coupled receptor/peropsin/retinochrome, and a neuropsin [8]. For the majority of bilaterians, it remains, however, unclear where these different opsins are expressed and whether given photoreceptor cells in different taxa are homologous or originated via evolutionary convergence (see $[5,7]$ for detailed studies).

Among bilaterians mollusks are textbook examples for eye evolution with designs as varied as the octopod camera eye, the nautiloid pinhole eye, the gastropod cup eye, or the camera-type eyes of strombid conchs [9]. Although most adult bivalves lack eyes, ark clams possess sophisticated compound eyes and scallops exhibit mirror-based eyes. Adult polyplacophorans lack cerebral eyes but certain species possess image-forming eyes embedded in their outermost tegmental shell valve layer (esthetes) [10]. Within earlier developmental stages, post-trochal eye spots are known from polyplacophoran trochophore larvae [10], and cerebrally innervated eyespots occur in gastropod and bivalve larvae [11]. Notably, there are also molluscan clades that neither possess eyes as adults nor during earlier developmental stages, such as the wormshaped aplacophorans or the tusk-shelled scaphopods (Fig. 1). These enigmatic animals live an infaunal, cryptic lifestyle as adults but possess free-swimming trochophore-like larvae, in which phototactic behavior has not been reported [12-16].

Reconstructing the evolutionary history of photoreceptors is challenging within the Mollusca. A recent study showed that the polyplacophoran mollusk Leptochiton asellus possesses three clusters of photoreceptors located in the apical, post-trochal, and the most posterior region of its trochophore larva $[17,18]$. The topography and cell lineage of the post-trochal eyes were used as arguments against their homology with cerebral eyes

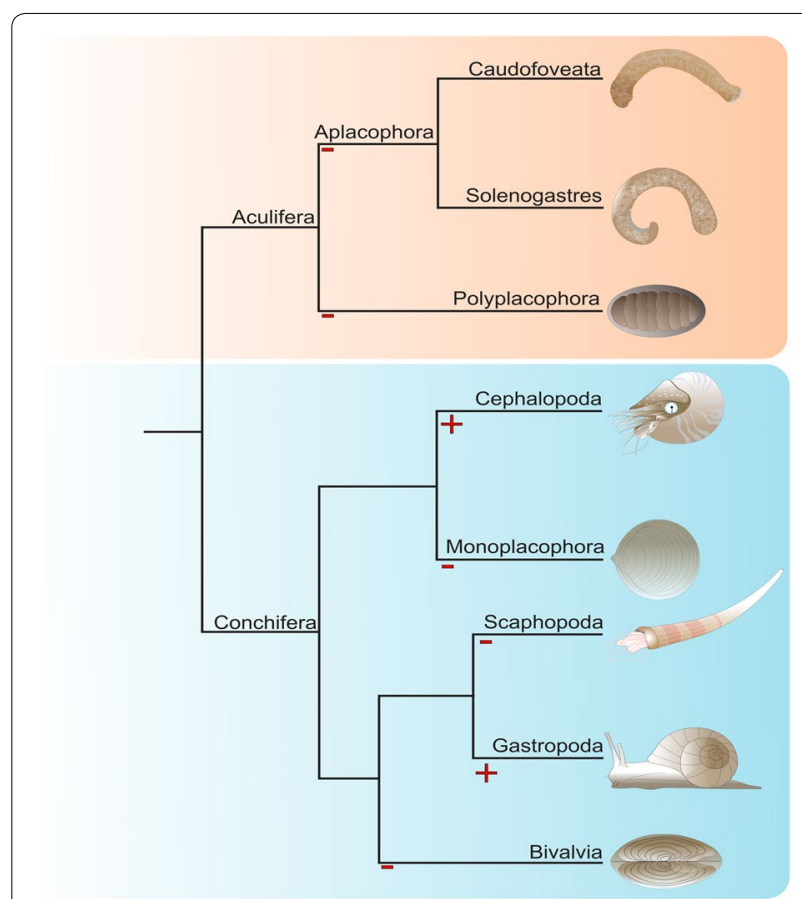

Fig. 1 The presence and absence of cerebral eyes in adult recent mollusks. The last common cephalopod and gastropod ancestors possessed probably a pair of adult cerebral eyes $(+)$, while the ancestors of all other molluscan clades most likely did not exhibit cerebral eyes (-). Adult polyplacophorans possess a sensory system with lenses in the tegmental layer of the shell valves, so-called esthetes. Certain bivalves evolved eyes associated with their mantle tissue. Phylogenetic analysis based on Smith et al. [28] Sketch drawing modified from Wollesen et al. [44]

of other mollusks and other bilaterians [19]. Despite this, all three types of polyplacophoran photoreceptors share gene expression profiles of cerebral eyes and express photoreceptor genes such as r-opsin and xenopsin, as well as genes implicated in the development of cerebral eyes in other taxa $[17,18]$. The latter genes include members of the Pax-Six-Eya-Dach network [paired box protein 6 (pax6), sine oculis homeobox gene 1/2 (six1/2), eyes absent (eya), and dachshund (dach)], transcription factors that are involved in the development of eyes, other sensory organs, and the brain $[20,21]$. Transient receptor potential cation channel $(\operatorname{trpC})$ is involved in phototransduction, myosinV (myoV) in intracellular r-opsin transport, while retinitis pigmentosa GTPase regulator (rpgr) is implicated in ciliary opsin targeting [22-24]. The 'cerebral' molecular fingerprint of polyplacophoran photoreceptors was interpreted as a heterotopic replication of the 'cerebral eyes' in the post-trochal region without a change in their underlying genetic circuitry [17]. According to this hypothesis, the cerebral eyes of polyplacophoran ancestors were replicated by a single saltatory event; this could be, for example, a single change in expression 
of a regulatory gene with concomitant changes of co-regulated downstream target genes. In the developmentally distinct post-trochal region, this would result in a pair of novel post-trochal eyes with underlying identical gene inventory to cerebral eyes. Caveats of this hypothesis are, however, that the underlying gene regulatory network is not known for polyplacophorans and that comparable data from closely related molluscan species are lacking.

In the present study, we took advantage of the case of an eyeless conchiferan mollusk, the scaphopod Antalis entalis, to investigate the molecular signature of eye, photoreceptor, and opsin functional degeneration. To this end, we searched for homologues of opsins and other eye or photoreceptor-related genes that have been described previously for the polyplacophoran mollusk $L$. asellus $[17,18]$. Two opsin genes, go-opsin and xenopsin, as well as pax6, six1/2, eya, dach, trpC, rpgr, and myosin $V$ have been identified to provide further insights into possible phototransduction pathways. We show that the scaphopod A. entalis and the polyplacophoran $L$. asellus express opsins in similar body regions and propose an evolutionary scenario of molluscan eye and photoreceptor evolution.

\section{Results}

\section{Phylogenetic and sequence analysis}

We detected putative sequences of go-opsin, xenopsin, dach, rpgr, six1/2, myosinV (myoV), pax6, eya, and trpC within the Antalis entalis (aen) transcriptome, and the predicted protein sequences of each of these genes cluster with their bilaterian orthologs in phylogenetic analyses
(Additional file 1: Figure S1). Two partial aen transcripts were found that encode peptides which fall within the xenopsin clade (Additional file 1: Figure S1a). The two peptide fragments do not overlap in the alignment and it is possible that they represent parts of the same gene, however, attempts to join the two fragments by PCR were unsuccessful (data not shown). We note that the Xenopsin clade is unsupported in our phylogenetic analysis, however, both partial sequences align well with other Xenopsins, and cluster with well-supported Xenopsin sequences from the more extensive analysis performed by Ramirez et al. [8]. The c-terminal Xenopsin sequence a2932192_2 was used for aen-xenopsin riboprobe synthesis for in situ hybridization. Both the c-terminal Xenopsin and the Go-opsin (aen transcript-60_140421) contain the characteristic 'NPXXY' motif and tripeptide for G-protein activation (Fig. 2; [18]). In the Xenopsin, the tripeptide is 'NKQ' (found in C-opsins and some other Xenopsins), while in the Go-opsin the tripeptide is 'HMK' (Fig. 2). The predicted amino acid sequence of go-opsin lacks the highly conserved lysine ('K296') in the retinal-binding domain (Fig. 2), which is completely conserved in all other opsins other than placopsins [25]. Every raw transcriptome read spanning this motif contained the same sequence, suggesting that the lack of a predicted lysine is not the result of a sequencing or assembly error (data not shown). In addition, the sequence spanning this motif has been amplified and Sanger sequenced, confirming the lack of the predicted lysine (Additional file 1). Structural prediction of aen-Go-opsin and comparison to bovine rhodopsin (PDB ID code 1U19) demonstrated the absence
Lottia gigantea V3ZSU7

Danio rerio A0A0R4ISV7

Drosophila melanogaster P06002

Acanthopleura granulata KX714606

Crassostrea gigas XP_011422477

Parastichopus parvimensis

Terebratalia transversa M9UW28

Antalis entalis transcript-60 140421

Tribolium castaneum B8K1S1

Branchiostoma floridae Q868G1

Platynereis dumerilii Q5SBP8

Danio rerio A8YXX6

Argopecten irradians KX550904

Lymnaea stagnalis FX190223

Hydra vulgaris F1LIN9

Antalis entalis a2932192 2

Trichoplax adhaerens B3RY65

Trichoplax adhaerens B3RZG1

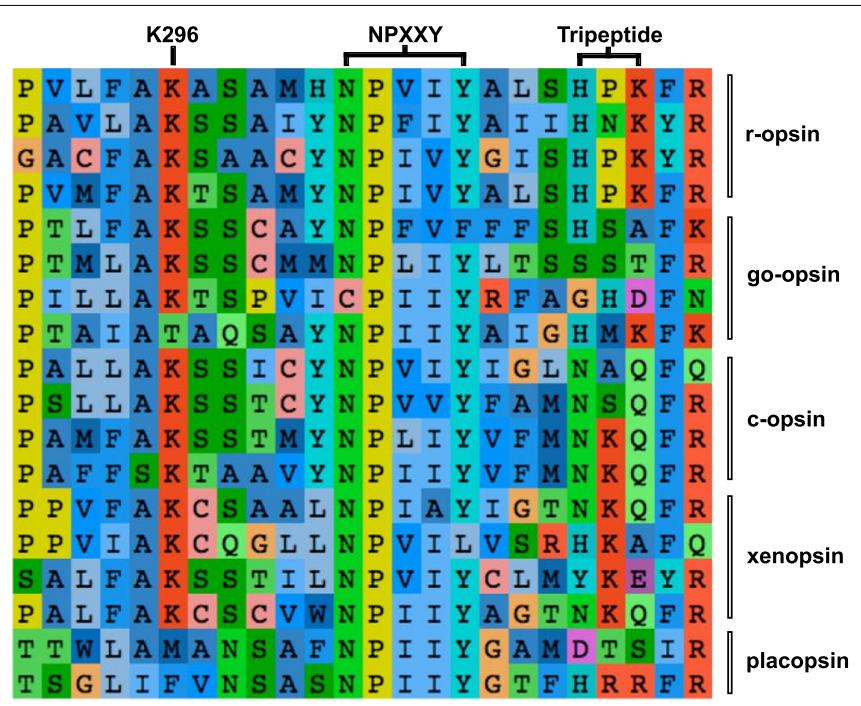

Fig. 2 The retinal-binding domain of scaphopod Go-opsin lacks the highly conserved lysine K296. Alignment of representative sequences from Ramirez et al. [8] highlight conserved motifs as per Vöcking et al. [18]. The highly conserved lysine (K) at position 296 is absent from placozoan opsins (='placopsins') and from aen-Go-opsin 
of any additional lysine residues within the retinal-binding pocket that may be able to compensate for the loss of K296 (as has been observed for Rhodopsin mutants in vitro, [26] (Fig. 3).

Clear single-copy orthologs were found for all other genes investigated, except six1/2. Three distinct $A$. entalis transcripts encoded proteins that fell within the six $1 / 2$ clade (Additional file 1: Figure S1g), suggesting that gene duplication has occurred in this lineage. The six $1 / 2$ sequence most similar to the previously investigated $L$. asellus six $1 / 2$ sequence was used for in situ hybridization.

No orthologs of R-opsin and C-opsin were identified in transcriptomes of developmental stages and adults of $A$. entalis ([27]; NCBI bioproject PRJNA357466; assembly available at https://zoology.univie.ac.at/open-data; [28], NCBI BioProject PRJNA72139).

\section{Gene expression analyses}

In situ hybridization experiments with riboprobes against $\operatorname{trp} C$ and xenopsin did not yield labeling of transcripts in any of the developmental stages examined (data not shown). PCR products were amplified from pooled larval cDNA, confirming that the genes are expressed during development, but perhaps at a concentration too low to be detected by hybridization techniques.

The earliest expression patterns detected in developmental stages of the scaphopod Antalis entalis are found in early trochophore larvae (Fig. 4a-c; Additional file 1: Figures S2-S8a-c). In the episphere, pax6+ cells are located below the cerebral pits, i.e., the invaginations of the cerebral ganglia placodes (Additional file 1: Figure S6a-c; [29-31]). Close to the pax6+ cells, six $1 / 2+$ cells are situated that may also be associated with the nervous system (Fig. 4c; Additional file 1: Figure S8a-c). More posteriorly dach is expressed in two cells close to the foregut (Additional file 1: Figure $\mathrm{S} 3 \mathrm{a}-\mathrm{c}$ ), while two myoV+ cells are located at the level of the prototroch (Additional file 1: Figure S5a-c). Goopsin is co-expressed with eya, six1/2, and rpgr posterior to the prototroch (Fig. 4a-c; Additional file 1:
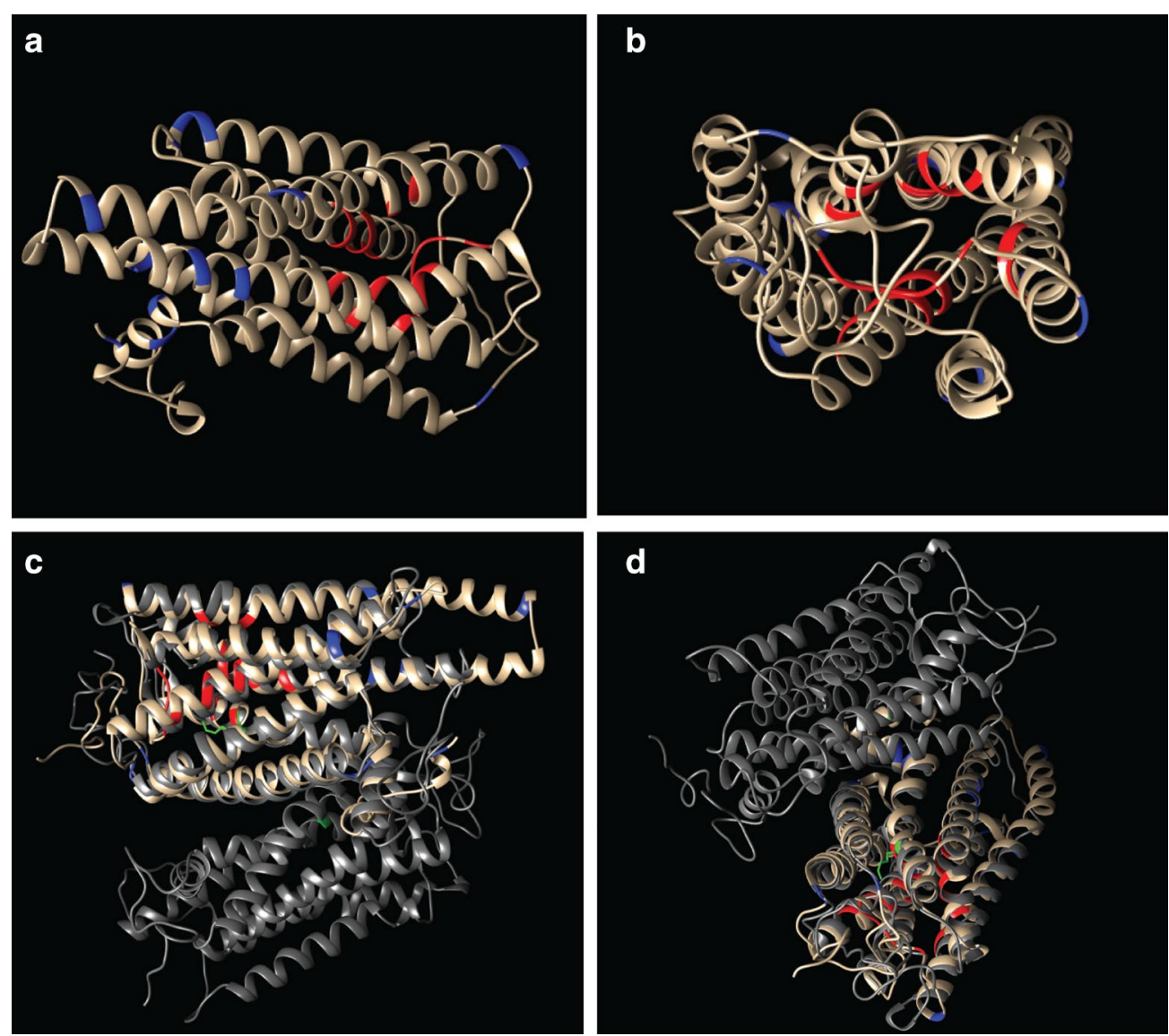

Fig. 3 Predicted secondary structure of Antalis entalis Go-opsin. Lysine residues (colored blue) are not found within the retinal-binding pocket (colored red) (a, b). The predicted secondary structure of aen-Go-opsin (beige) closely aligns with that of bovine Rhodopsin (two subunits shown, gray, aen-Go-opsin is aligned with a subunit) (c, d). The position of K296 in the bovine subunits is indicated in green 
Figures S2a-c, S4a-c, S7a, S8a). Posterior to the mouth dach is expressed in two bilateral cells embedded in the epidermis (Additional file 1: Figure S3a-c). A pair of pax $6+$ cells is located in the prospective foot, a region in which eya + cells and dach + cells are also present (Fig. 4b; Additional file 1: Figures S3a-c, S4a-c, S6a-c).

Early mid-stage trochophores express go-opsin in two apical cells located in the lateral episphere adjacent to the trochoblasts, and in two cells of the anterior inner mantle posterior to the prototroch (Figs. $4 \mathrm{~d}-\mathrm{f}$; 6a; Additional file 1: Figure S2d-f). No shading pigments are associated with these cells. The apical goopsin + cells are flask-shaped, send processes to the apical surface (Fig. 4f), and connect via axons to the neuropilar plexus underlying the apical organ (data not shown). These cells appear to co-express go-opsin, eya and myo $V$, however, we could not unequivocally determine that expression was located within the same cells (Figs. 4g, h; 6a). Pax6 and six1/2 are expressed in other flask-shaped apical organ cells, i.e., are not coexpressed with go-opsin, eya, and myoV (Figs. 4i; 6a; Additional file 1: Figure S6d-f). Six1/2 and dach are expressed in the region of the cerebral ganglia (Fig. 5a, f; Additional file 1: Figures S3d-f, S8d-f). Go-opsin, eya, six 1/2, and myoV appear to be co-expressed in two cells of the anterior inner mantle, posterior to the prototroch (Figs. 4d-i; 5a). Eya and six $1 / 2$ are expressed in the region that connects the hyposphere with the episphere (Figs. 4g, i; 5d, f). The prototroch expresses rpgr, while six1/2, dach, eya, myoV are expressed in several additional regions of the mantle (Figs. $4 \mathrm{~g}-\mathrm{i} ; 5 \mathrm{a}, \mathrm{c}$, e; Additional file 1: Figures S3d-f, S7d-f). Dach+, eya+, myoV+, pax6+ and six $1 / 2+$ cells are found in different regions of the foot and form two bilateral co-expression domains in the ventral posterior foot (Figs. $4 \mathrm{~g}-\mathrm{i}$; 5a, b, d-f; 6a; Additional file 1: Figures S3d-S5d, S6d, e). Dach, six1/2, rpgr, eya, and myoV appear to be coexpressed in a region of the pavilion (Figs. $4 \mathrm{~g}-\mathrm{i} ; 5 \mathrm{a}, \mathrm{c}-\mathrm{e}$; 6a; Additional file 1: Figures S3d, S4e, S5e, S7e).
At later stages, the episphere invaginates and accordingly the prototroch is situated more anteriorly [32]. Consequently, both apical go-opsin + cells that appear to co-express eya and myoV are located in the interior of mid-stage trochophores (Fig. 4j-l; Additional file 1: Figures S4h, S5i). Other apical cells also express pax6 and six $1 / 2$, while six $1 / 2+$ cells are also present in the region of the cerebral and pedal ganglia (Fig. 4m; Additional file 1: Figures S6h, j, S8h, j). Eya is expressed in the region connecting the hyposphere and episphere (Fig. $4 \mathrm{k}$ ). Both post-trochal go-opsin + cells are still visible in the mantle and still appear to co-express eya, six1/2, and myoV (Fig. 4j-m; Additional file 1: Figures S2g-j). Dach, eya, myoV, pax6 and six $1 / 2$ are expressed in diverse regions of the mantle (Fig. 4j-m; Additional file 1: Figures S3g, $\mathrm{S} 4 \mathrm{~g}-\mathrm{i}, \mathrm{S} 5 \mathrm{~g}-\mathrm{j}, \mathrm{S} 6 \mathrm{~g}-\mathrm{j}, \mathrm{S} 8 \mathrm{~g}-\mathrm{j})$. The foot houses dach+, myoV+, and pax6+ cells (Additional file 1: Figures S3h, S5i, S6h, i) and portions of the pavilion express myoV and pax6 (Fig. 4l; Additional file 1: Figures S5h, S6h). Rpgr+ cells were not detected in the mid-stage trochophore larva (Additional file 1: Figure S7g-j).

\section{Discussion}

\section{Are scaphopod go-opsins functional?}

Go-opsins are a poorly characterized, but evolutionarily ancient, group of opsin proteins that have been lost in ecdysozoans and many vertebrates $[18,25]$. They were first discovered in the ciliary receptors of the distal retina in the mantle eyes of scallops [33]. In annelids, go-opsin1 exhibits a lambda absorption maximum of $488 \mathrm{~nm}$, and these photoreceptors are involved in the phototactic response to light in trochophores and in the mediation of the shadow reflex in adults [34,35]. Therefore, Go-opsins function in the mediation of light responses in both annelids and mollusks.

In all neuralians studied so far, all opsins are linked via a highly conserved lysine (Schiff base) to a chromophore to form a visual pigment [25]. A covalent interaction between the Schiff base in the seventh transmembrane

\footnotetext{
(See figure on next page.)

Fig. 4 Go-opsin + cells and potentially co-expressed genes in developmental stages of the scaphopod Antalis entalis. Anterior faces up in all aspects. Early trochophores (a-c) express go-opsin in the region around the mouth (asterisk), while eya+ cells are distributed throughout the interior of the larva. Six $1 / 2+$ cells are located in the region of the foot (black arrow), in the prospective cerebral ganglia (cg), and in two other cells (white-lined arrow). In early mid-stage trochophores ( $\mathbf{d}$-i) go-opsin + cells are located in the inner anterolateral mantle margin (arrows). Two other go-opsin+ cells are located in the lateral episphere adjacent to the trochoblasts (arrowheads). f Axons of the apically located go-opsin+ cells run to the neuropil of the apical organ (double-arrowhead) and processes of these cells penetrate the epidermis and are in contact with the environment (not shown here, only visible in the confocal stack). Each arrowhead labels a go-opsin + cell. g Putative co-expression of eya with both pairs of go-opsin + cells. $\mathbf{h}$ Putative co-expression of myoV with both pairs of go-opsin + cells. $\mathbf{i}$ Putative co-expression of six $1 / 2$ with the posterior pair of go-opsin+ cells. In mid-stage trochophores (j-m), go-opsin, eya, myoV and six $1 / 2$ are probably co-expressed in both apical cells that migrated in posterior direction (arrowheads) and in both post-trochal cells that are located in the anterolateral inner mantle margin (white-lined arrows). Both apical six $1 / 2+$ cells (arrowheads) are probably different cells than the go-opsin+, eya+, myoV+ cells since they derive from a different location at earlier stage (c.f. Additional file 1: Figure S8f). See Additional file 1: Figures S2, S4, S5 and S8 for a detailed description of the expression domains. $f$ foot $p t$ prototroch. Scale bars: $50 \mu \mathrm{m}$ for image of each developmental stage
} 


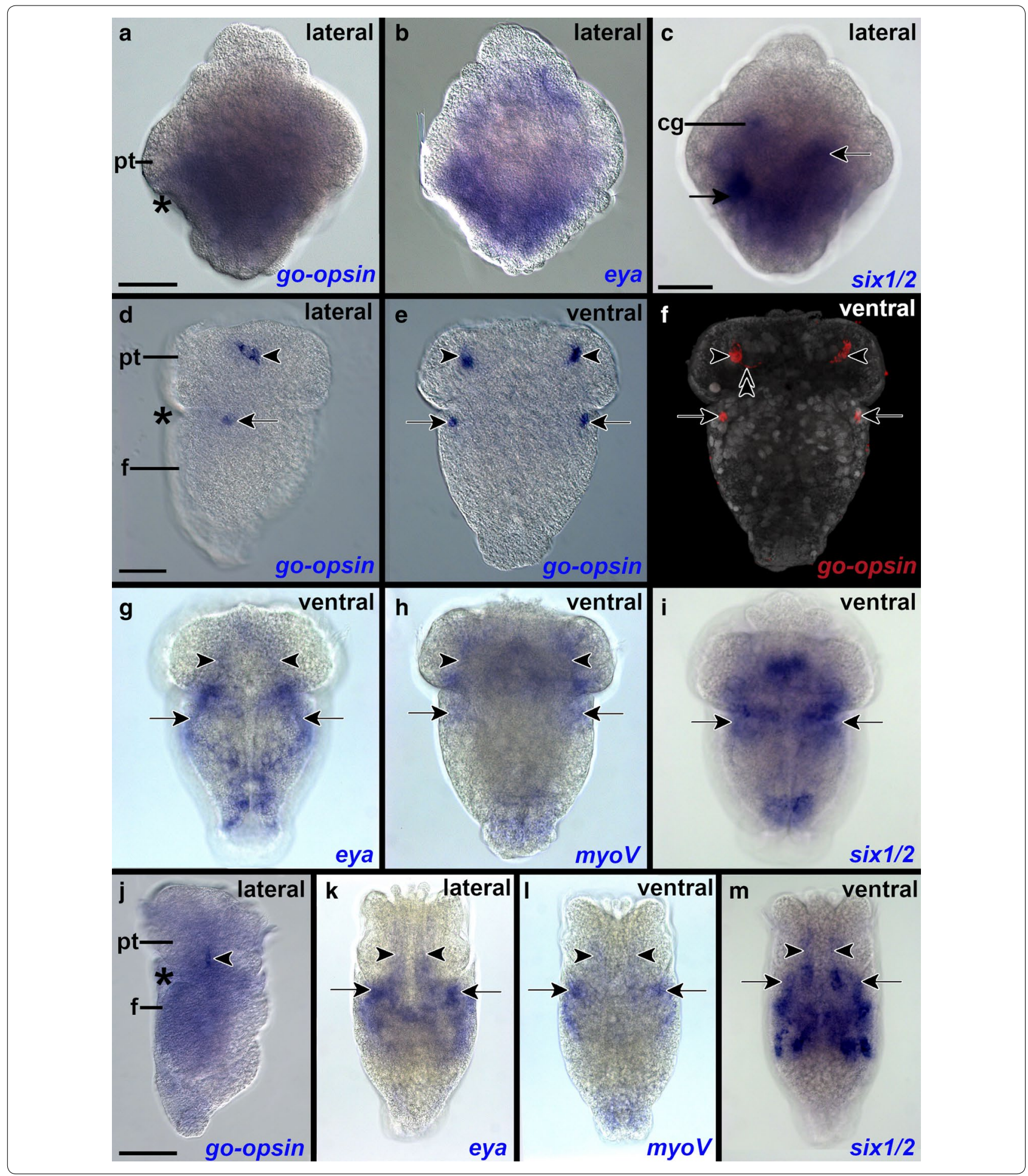

helix and the retinal chromophore leads to photosensation [36, 37]. In the scaphopod Antalis entalis, the predicted Go-opsin amino acid sequence does not contain this lysine (K296, named after the position of the residue in bovine Rhodopsin) (Fig. 2). Absence of the Schiff base is so far only known from fungal, haloarchael, and placozoan opsin-like receptors $[25,38,39]$, where it was hypothesized that they may be unable to detect light [25]. However, in vitro experiments indicate that this may not necessarily be the case. Mutation experiments on bovine 


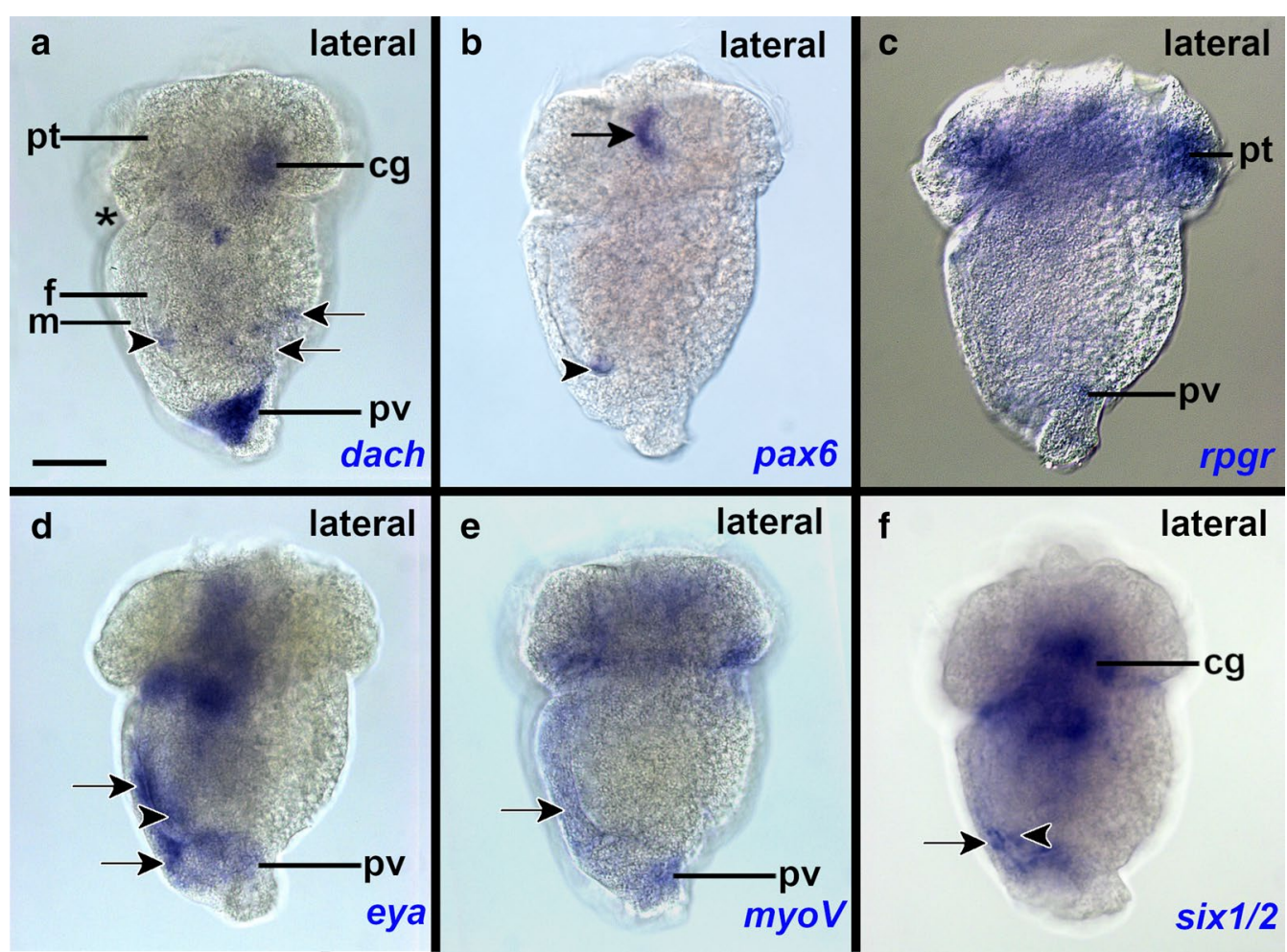

Fig. 5 Putative sensory epithelia in the hyposphere of the scaphopod trochophore. Anterior faces up and ventral to the left in all aspects. See Fig. 4 for description of other expression domains of respective genes. The asterisk labels the mouth. $\mathbf{a}$ Dach is expressed in the region of the cerebral ganglia (cg), the pavilion (pv), the anterolateral and posterior foot (arrowhead), the posterior dorsal mantle region (arrows), and the lateral foot. $\mathbf{b}$ Two pax6+ flask-shaped cells are part of the lateral apical organ (black arrow) and two pax6+ cells are located in the posterior foot (white-lined arrowhead). $\mathbf{c}$ Rpgr is expressed in the trochoblasts of the prototroch and cells of the pavilion. $\mathbf{d}$ Eya is expressed in cells of the pavilion, the posterior ventral mantle (white-lined arrows), and the posterior foot (arrowhead). e MyoV+ cells are located in the ventral mantle (arrow) and the pavilion. $\mathbf{f}$ Six $1 / 2+$ cells are located in the posterior ventral mantle (arrow) and the posterior foot (arrowhead) as well as the inner pavilion. pt prototroch. Scale bars: $50 \mu \mathrm{m}$
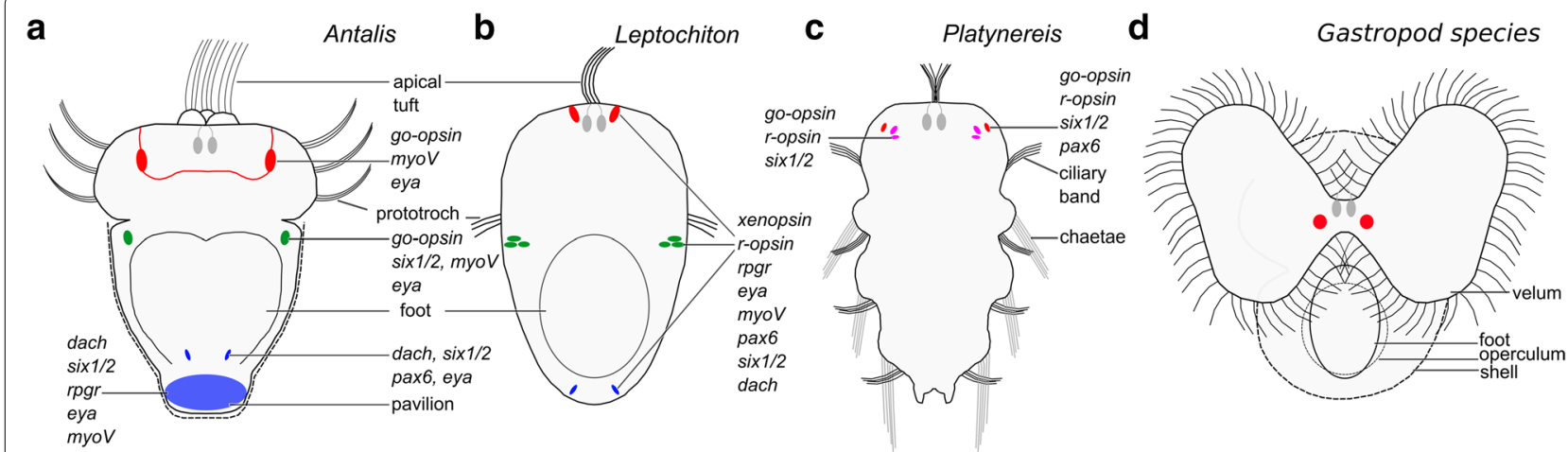

Fig. 6 Photoreceptors and gene expression profiles of molluscan and annelid larvae. Ventral views and anterior faces up. The apical (larval) photoreceptors (red) of the trochophore of the scaphopod mollusk Antalis entalis (a), the trochophore of the polyplacophoran mollusk Leptochiton asellus (b), the $72 \mathrm{~h}$ after fertilization old larva of the polychaete annelid Platynereis dumerilii (c), and a generalized gastropod veliger larva (d) may be homologous based on their cerebral innervation, ontogeny, location close to the apical organ (cells labeled in gray), and their molecular fingerprint. Note that the eyes of gastropod and bivalve veliger larvae have not been characterized based on their gene expression profiles. The scaphopod and polyplacophoran post-trochal photoreceptors (green) are probably homologous since they are located posterior to the prototroch in the mantle and express similar genes. Polyplacophorans possess a pair of posteriormost photoreceptors (blue) in the mantle. The latter may be homologous to scaphopod posterior most expression domains in the pavilion (posterior mantle opening) or the posterior ventral foot based on their location and gene expression profile. The adult eyes of $P$. dumerilii are labeled in pink 
Rhodopsin revealed that proteins in which K296 had been substituted with another amino acid were constitutively active, i.e., were able to activate signaling via the G-protein transducin in the absence of a chromophore [40]. Further experiments also showed that light-dependent activation for these K296 mutants could be rescued by modification of another residue within the active site to a lysine [26]. In these cases, the protein regains the ability to form a pigment with 11-cis-retinal and to activate G-proteins in response to light, although the spectral properties are slightly altered $[26,40]$. Prediction of the secondary structure of $A$. entalis Go-opsin revealed that there are no other lysine residues within the retinal-binding pocket (Fig. 3), therefore rescue of responsiveness to light is unlikely to have occurred via this mechanism. Given this, and that the aen-go-opsin sequence contains a domain for G-protein activation (NPIIY motif and tripeptide in Fig. 2), we speculate that the scaphopod Go-opsin may still be functional as a sensory receptor of unknown modality.

\section{Homology of polyplacophoran and remnant scaphopod apical and post-trochal photoreceptors}

Aen-go-opsin + cells are located in the vicinity of the trochoblasts in the episphere, i.e., a region that may be part of the apical organ (Fig. 4a-c; [32]. Both latter cells are flask shaped, their dendritic processes penetrate the epidermis and their axons run in the direction of the neural plexus underlying the apical organ (data not shown). Therefore, they resemble apical chemoreceptors [32, 41]. The other pair of aen-go-opsin + cells is present in the inner anterolateral mantle margin posterior to the prototroch in the early mid-stage trochophore (Fig. $4 \mathrm{~d}-\mathrm{f}$ ). None of the aen-go-opsin + cells are accompanied by cells with discrete shading pigments which are required for directional photoreception. Recent studies have demonstrated positive photoresponse behavior without any discrete shading pigment in brachiopods [42], indicating that the opaqueness of the larval body may be used for shielding. Photoreceptors of other mollusks are arranged in a strikingly similar fashion as those of the scaphopod A. entalis (Fig. 6a, b). The trochophore of the polyplacophoran Leptochiton asellus also possesses a pair of photoreceptor cells in the apical organ or close to it, and the veliger larvae of gastropods and bivalves exhibit cerebrally innervated eyes close to the apical organ (Fig. 6b, d; $[17,18])$. The polyplacophoran trochophore additionally possesses a pair of post-trochal larval eyes reminiscent of the scaphopod condition, as well as another pair of photoreceptors at the posteriormost end of the trochophore (Fig. 6b; [17, 18]). Like scaphopod and polyplacophoran trochophore larvae, adult scallops possess photoreceptors within the mantle, albeit within mirror eyes located on the tips of tentacles extending from the middle mantle fold [33]. In contrast to scaphopods (this study), bivalves [33], and gastropods [8], go-opsin has probably been secondarily lost during evolution in polyplacophorans and cephalopods (go-opsin appears to be absent in the genome of Octopus bimaculoides and no polyplacophoran genome has been published so far). In polyplacophorans, go-opsin has been functionally replaced by $r$-opsin and xenopsin within photoreceptors (Fig. 6b; $[8,17,18$, $35])$.

\section{Crucial phototransduction machinery genes are not expressed in scaphopod photoreceptors}

To infer whether the scaphopod go-opsin+ cells possess the genetic inventory for phototransduction, we carried out in situ hybridization experiments on genes involved in phototransduction, ciliary opsin targeting, intracellular R-opsin transport, and eye development as previously reported for the polyplacophoran $L$. asellus $[17,18]$. While in L. asellus all three groups of photoreceptors co-express xenopsin, r-opsin, eya, dach, six 1/2, $m y o V$, tryp $C$, and rpgr $[17,18]$, only few of these genes are potentially co-expressed in the scaphopod go-opsin+ cells (Fig. 6a, b). Aen-go-opsin appears to be co-expressed with myoV and eya in the apical cells and six 1/2, myoV, and eya in the post-trochal cells, but no co-expression was observed with $\operatorname{trpC}$, rpgr, pax6, or dach (Fig. 6a). In contrast to apical and post-trochal go-opsin+ cells which do not express a number of crucial genes implicated in phototransduction or eye development, numerous important phototransduction machinery genes (but not opsins) appear to be co-expressed in few cells of the posterior ventral foot (dach, six1/2, pax6, eya) and the pavilion (dach, six1/2, rpgr, eya, myoV) (Fig. 6a). This resembles the condition found in the polyplacophoran posterior most photoreceptors that co-express dach, six1/2, eya, pax6, rpgr, and myoV in r-opsin+/xenopsin + cells (Fig. 6b; $[17,18]$ ). While no orthologs of $r$-opsin or c-opsin were found within publicly accessible scaphopod transcriptomic resources, we cannot discount that some of these genes may be co-expressed with xenopsin, for which a partial sequence was discovered within the Antalis entalis developmental transcriptome. We were unable to amplify this gene from larval cDNA, therefore Aen-xenopsin may be lowly expressed, or may only be expressed during a very short developmental time frame that has not been considered in our study. The latter condition has been found in cave fish species and their closely related surface-dwelling species that exhibit significantly different opsin expression levels depending on the need for short- or long-wavelength sensitivity [43]. Interestingly, only one of the genes identified here (six1/2) could be found by BLAST within an additional 
Antalis entalis transcriptome dataset [28], (NCBI BioProject PRJNA72139), presumably generated from adult tissue, indicating that expression of the majority of these genes may be restricted to larval stages.

\section{An evolutionary scenario of molluscan photoreceptor evolution}

Based on their 'cerebral' expression profile, their topological location, and their distinct cell lineage from other mollusks or annelids, the polyplacophoran post-trochal eyes are argued to have arisen by heterotopic replication from ancestral cerebral eyes under retention of transcriptional activity of genes involved in phototransduction and eye development [17]. Our study highlights a similar location of apical and post-trochal photoreceptors in polyplacophoran and scaphopod trochophores, respectively (Additional file 1: Table S1). The polyplacophoran condition is most similar to the scaphopod early midstage trochophore, considered to be the 'phylotypic stage' in which staggered Hox gene expression bears most resemblance to the ancestral bilaterian condition (Fig. 6a, b; [44]).

We propose homology of the apical photoreceptor cells of scaphopods, polyplacophorans, and annelids (Fig. 6ac; [35]). Spatial expression of opsin genes has not been investigated in gastropod and bivalve larvae, however, based on their proximity to the apical organ and their cerebral innervation their larval eyes may be homologous to the scaphopod and polyplacophoran apical photoreceptors (Fig. 6d; Additional file 1: Table S1). Due to a similar location in the trochophore larva and a similar gene expression profile, we propose homology of the post-trochal (mantle) photoreceptors of scaphopods and polyplacophorans. Although adult scallops also express go-opsin in their photoreceptors within their mantlebased mirror eyes, we hesitate to consider this as support for our hypothesis, since bivalve adult eyes have evolved several times independently and were probably not present in the last common bivalve ancestor (Fig. 1; [33]). Several genes co-expressed in the posterior most polyplacophoran photoreceptors are also expressed in a domain in the posterior scaphopod foot. However, the expression of an opsin in this region could not been proven for scaphopods and therefore the homology of these regions remains unclear.

Given the similarity between polyplacophoran and remnant scaphopod post-trochal photoreceptors, we argue that the evolution of these photoreceptors via heterotopic replication from cerebral eyes may have occurred in the molluscan stem lineage and not only in the polyplacophoran stem lineage. If correct, larval post-trochal/mantle edge-associated eyes could therefore be considered a molluscan (not a polyplacophoran) synapomorphy, with loss of post-trochal (mantle margin) photoreceptors in other mollusks. Alternatively, the evolution of post-trochal eyes may have occurred via the gradual co-option of photoreceptor gene expression to the post-trochal region in both polyplacophorans and scaphopods. Although additional data are needed, we consider the first evolutionary scenario more parsimonious as it could have occurred via the change of expression of a single regulatory gene, while stepwise co-option of single genes of a gene regulatory network requires several evolutionary events.

\section{Conclusions}

Our results indicate that the scaphopod go-opsin + cells represent former photoreceptors which have probably evolved into receptors of another sensory modality. This degeneration can be seen in the light-insensitive Goopsin, the loss of photoreceptor shielding pigments, and the loss of expression of several genes involved in phototransduction and eye development. The similar topographical constellation of remnant photoreceptor cells with functional photoreceptors in polyplacophorans suggests that the last common molluscan ancestor also possessed apical, post-trochal, and probably posterior photoreceptors, which represent previously unrecognized molluscan synapomorphies.

\section{Methods}

\section{Ethics, collection and culture of animals}

Adults of the scaphopod Antalis entalis Jeffreys 1869 were collected from approximately $25 \mathrm{~m}$ depth by the staff of the research vessel Neomys off the coast of Roscoff (France) in the summer of 2014 and 2017. Animals spawned and developmental stages were reared at $18-20{ }^{\circ} \mathrm{C}$ as described previously [16].

\section{RNA extraction and fixation of animals for in situ hybridization experiments}

Several hundred individuals of early cleavage stages to settled metamorphosed individuals were investigated. All developmental stages were carefully anesthetized in $7.14 \% \mathrm{MgCl}_{2}$ before fixation for in situ hybridization experiments as previously described [16].

\section{Alignment, phylogenetic analysis and secondary structure prediction}

Candidate genes were identified by BLAST searches against the published transcriptomes of the scaphopod A. entalis ([16, 27]; NCBI bioproject PRJNA357466; assembly available at https://zoology.univie.ac.at/opendata/) were derived from pooled RNA from several hundred specimens of early embryos to postmetamorphic individuals. Phylogenetic analyses were performed for 
each of the predicted protein sequences building upon the analyses of Vöcking et al. $[17,18]$ and Ramirez et al. [8]. Sequences were aligned and manually edited within AliView [45], and maximum likelihood phylogenetic analyses were performed using RAxML 8.2.11 [46] with automatic model selection, gamma model of rate heterogeneity, and 100 bootstrap replicates. Phylogenetic trees were visualized and edited in FigTree [47]. Protein secondary structure and ligand binding prediction were performed using I-TASSER [48]. Resulting PDB models were viewed, annotated, and aligned with bovine rhodopsin (PDB ID code 1U19) in UCSF Chimera [49].

\section{Molecular isolation of RNA transcripts}

A first-strand cDNA Synthesis Kit for rt-PCR (Roche Diagnostics GmbH, Mannheim, Germany) was used for first-strand cDNA synthesis of the RNA pooled from different developmental stages of $A$. entalis [16]. Identified gene sequences were used to design gene-specific primers (see Additional file 1) and PCR products were size fractioned by gel electrophoresis, gel bands of the expected lengths were excised and cleaned up using a QIAquick Gel Extraction Kit (QIAgen, Hilden, Germany). Cleanedup products were cloned by insertion into pGEM-T Easy Vectors (Promega, Mannheim, Germany), as per the manufacturer's protocol. Plasmid minipreps were grown overnight, cleaned up with the QIAprep Spin Miniprep Kit (QIAgen), and sent for sequencing to confirm identity.

\section{Probe synthesis and whole-mount in situ hybridization}

Riboprobe templates were amplified via standard PCR from miniprep plasmids using M13 forward and reverse primers as described previously [16]. In vitro transcription reactions were performed with these templates, digoxigenin-UTP (DIG RNA Labeling Kit, Roche Diagnostics), and SP6/T7 polymerase (Roche Diagnostics $\mathrm{GmbH}$ ) for the synthesis of antisense riboprobes, according to the manufacturer's instructions. For whole-mount in situ hybridization experiments, specimens were rehydrated into PBT (phosphate buffered saline $+0.1 \%$ Tween-20) and treated with Proteinase$\mathrm{K}$ at $37{ }^{\circ} \mathrm{C}$ for $10 \mathrm{~min}(30 \mu \mathrm{g} / \mathrm{mL}$ in PBT). Specimens were pre-hybridized in hybridization buffer for $4-10 \mathrm{~h}$ at $58{ }^{\circ} \mathrm{C}$ (see [16] for details). Hybridization was performed at the same temperature with probe concentrations ranging between 1 and $2 \mu \mathrm{g} / \mathrm{mL}$ for $21-24 \mathrm{~h}$. A DIG-labeled AP antibody was used at a dilution of 1:2500 in blocking solution at $4{ }^{\circ} \mathrm{C}$ overnight. Color development in the NBT/BCIP/alkaline phosphatase buffer solution took $6-24 \mathrm{~h}$ at $4{ }^{\circ} \mathrm{C}$. Some specimens were counterstained with DAPI to visualize cell nuclei (Sigma-Aldrich, St. Louis, MO, USA). A minimum of 30 individuals per stage were investigated. The majority of whole-mount preparations were cleared in a solution of 2,2'thiodiethanol (Sigma-Aldrich), mounted on objective slides and analyzed. Preparations were documented with an Olympus BX53 Microscope (Olympus, Hamburg, Germany). In addition, developmental stages were scanned with a Leica confocal SP5 II microscope (Leica Microsystems, Wetzlar, Germany) using brightfield, autofluorescence, and reflection mode scans to document the precise cellular location of transcripts [50]. If necessary, images were processed with Adobe Photoshop 9.0.2 software (San Jose, CA, USA) to adjust for contrast and brightness. Sketch drawings were created with Adobe Illustrator CC 2015.1.0 (Adobe Systems, Inc., San Jose, CA; USA). The absence of staining caused by endogenous alkaline phosphatases has previously been demonstrated, and expression patterns shown within this study were distinct from those of offtarget controls ([16, 44]; Additional file 1: Figure S9)

\section{Supplementary information}

Supplementary information accompanies this paper at https://doi. org/10.1186/s13227-019-0140-7.

Additional file 1: Figures S1a-h. Phylogenetic analyses. Figures S2-S9. Additional gene expression patterns. Table S1. Primer and Go-opsin sequences.

\section{Abbreviations}

Aen: Antalis entalis; BCIP: 5-brom-4-chlor-3-indoxylphosphat; BLAST: Basic local alignment search tool; C-opsin: Ciliary opsin; cDNA: Complementary deoxyribonucleic acid; cg: Cerebral ganglia; DIG: Digoxigenin; eya: eyes absent; f: Foot; dach: dachshund; NBT: Nitro blue tetrazolium; NCBI: National center for biotechnology information; myoV: myosinV; pax6: paired box protein 6; PBT: Phosphate-buffered saline with Triton X-100; pcr: Polymerase chain reaction; pv: Pavilion; pt: Prototroch; RNA: Ribonucleic acid; r-opsin: Rhabdomeric opsin; rpgr: retinitis pigmentosa GTPase regulator; six 1/2: sine oculis homeobox gene 1/2; trpC: transient receptor potential cation channel.

\section{Acknowledgements}

TW thanks the staff from the research vessel Neomys [Station Biologique Roscoff (SBR), Roscoff] for collecting adult scaphopods. The authors thank two anonymous reviewers for their comments on a previous version of this manuscript.

\section{Authors' contributions}

TW designed the study together with CMD. TW raised the scaphopod developmental stages and carried out all experiments. CMD performed the phylogenetic analysis and predicted the secondary structure of Go-opsin. TW drafted the manuscript and CMD commented on the manuscript. DA commented on a later version of the drafted manuscript. All authors read and approved the final manuscript.

\section{Funding}

TW is supported by an Erwin Schrödinger grant from the Austrian Science Foundation (FWF): Grant Agreement No. J4198. The research leading to these results received partial funding from the European Union's Horizon 2020 research and innovation programme under Grant Agreement No. 730984, ASSEMBLE Plus project to TW. CM is supported by an Advance Queensland Fellowship. TW and DA thank EMBL Heidelberg for financial support.

\section{Availability of data and materials}

All sequences analyzed in this study have been published on publicly accessible websites. 
Ethics approval and consent to participate

Not applicable.

\section{Consent for publication}

Not applicable.

\section{Competing interests}

The authors declare that they have no competing interests.

\section{Author details}

${ }^{1}$ EMBL, Meyerhofstraße 1, 69117 Heidelberg, Germany. ${ }^{2}$ Australian Rivers Institute, Griffith University, 170 Kessels Road, Nathan, QLD 4111, Australia.

Received: 16 July 2019 Accepted: 25 September 2019

Published online: 19 October 2019

\section{References}

1. Audino JA, Serb JM, Marian JEAR. Ark clams and relatives (Bivalvia: Arcia) show convergent morphological evolution associated with lifestyle transitions in the marine benthos. Biol J Linn Soc. 2019;2019(126):866-84.

2. Bok MJ, Porter ML, Nilsson DE. Phototransduction in fan worm radiolar eyes. Curr Biol. 2017;27:R681-701.

3. Lamb TD, Collin SP, Pugh EN. Evolution of the vertebrate eye: opsins, photoreceptors, retina and eye cup. Nat Rev Neurosci. 2007;8:960-76.

4. Salvini-Plawen LV, Mayr E. On the evolution of photoreceptors and eyes. New York: Plenum; 1977

5. Arendt D, Tessmar-Raible K, Snyman H, Dorresteijn AW, Wittbrodt J. Ciliary photoreceptors with a vertebrate-type opsin in an invertebrate brain. Science. 2004:306(5697):869-71.

6. Arendt D, Wittbrodt J. Reconstructing the eyes of Urbilateria. Philos Trans R Soc Lond B Biol Sci. 2001:356(1414):1545-63.

7. Randel N, Bezares-Calderón LA, Gühmann M, Shahidi R, Jékely G. Expression dynamics and protein localization of rhabdomeric opsins in Platynereis larvae. Integr Comp Biol. 2013;53:7-16.

8. Ramirez DM, Pairett AN, Pankey MS, Serb JM, Speiser DI, Swafford AJ, Oakley $\mathrm{TH}$. The last common ancestor of most bilaterian animals possessed at least nine opsins. Genome Biol Evol. 2016;8(12):3640.

9. Ponder WF, Lindberg DR. Phylogeny and evolution of the Mollusca. Berkely: University of California Press; 2007

10. Eernisse DJ, Reynolds PD. Polyplacophora. The microscopic anatomy of invertebrates. Mollusca I, vol. 5. Wiley: New York; 1994. p. 55-110.

11. Nielsen C. Trochophore larvae: cell-lineages, ciliary bands, and body regions. 1. Annelida and Mollusca. J Exp Zool. 2004;302B:35-68.

12. Okusu A. Embryogenesis and development of Epimenia babai (Mollusca Neomeniomorpha). Biol Bull. 2002;203:87-103.

13. Reynolds PD. The Scaphopoda. Adv Mar Biol. 2002;42:137-236.

14. Todt C, Wanninger A. Of test, trochs, shells, and spicules: development of the basal mollusk Wirenia argentea (Solenogastres) and its bearing on the evolution of trochozoan larval key features. Front Zool. 2010;7:6.

15. Wanninger A, Wollesen T. Mollusca. In: Wanninger A, editor. Evolutionary developmental biology of invertebrates Lophotrochozoa (Lophotrochozoa), vol. 2. Vienna: Springer; 2015. p. 103-53.

16. Wollesen T, Rodríguez Monje SV, McDougall C, Degnan BM, Wanninger A. The ParaHox gene Gsx patterns the apical organ and central nervous system but not the foregut in scaphopod and cephalopod mollusks. EvoDevo. 2015;6:41

17. Vöcking $\mathrm{O}$, Kourtesis I, Hausen $\mathrm{H}$. Posterior eyespots in larval chitons have a molecular identity similar to anterior cerebral eyes in other bilaterians. EvoDevo. 2015;6:40

18. Vöcking $\mathrm{O}$, Kourtesis I, Tumu SC, Hausen H. Co-expression of xenopsin and rhabdomeric opsin in photoreceptors bearing microvilli and cilia. eLife. 2017;6:e23435.

19. Henry JQ, Okuso A, Martindale MQ. The cell lineage of the polyplacophoran, Chaetopleura apiculata: variation in the spiralian program and implications for molluscan evolution. Dev Biol. 2004;272:145-60.

20. Bassham S, Postlethwait JH. The evolutionary history of placodes: a molecular genetic investigation of the larvacean urochordate Oikopleura dioica. Development. 2005;132:4259-72.
21. Kozmik Z, Holland N, Kreslova J, Oliveri D, Schubert M, Jonasova K, Holland L, Pestarino M, Benes V, Candiani S. Pax-Six-Eya-Dach-network during amphioxus development: conservation in vitro but context specificity in vivo. Dev Biol. 2007;306:143-59.

22. Vale RD. The molecular motor toolbox for intracellular transport. Cell. 2003;112:467-80.

23. Wätzlich D, Vetter I, Gotthardt K, Miertzschke $M$, Chen $Y X$, Wittinghofer A, Ismail S. The interplay between RPGR, RDE $\delta$ and Arl2/3 regulate the ciliary targeting of farnesylated cargo. EMBO Rep. 2013;14:465-72.

24. Yau KW, Hardie RC. Phototransduction motifs and variations. Cell. 2009;139:246-64.

25. Feuda R, Hamilton SC, Mclnerney JO, Pisani D. Metazoan opsin evolution reveals a simple route to animal vision. PNAS. 2012;109:18868-72.

26. Devine EL, Oprian DD, Theobald DL. Relocating the active-site lysine in rhodopsin and implications for evolution of retinylidene proteins. PNAS. 2013:110:13351-5.

27. De Oliveira AL, Wollesen T, Kristof A, Scherholz M, Redl E, Todt C, Bleidorn C, Wanninger A. Comparative transcriptomics enlarges the toolkit of known developmental genes in mollusks. BMC Genomics. 2016;17:905.

28. Smith SA, Wilson NG, Goetz FE, Feehery C, Andrades SCS, Rouse GW, Giribet G. Dunn CW Resolving the evolutionary relationships of molluscs with phylogenomic tools. Nature. 2011;480:364-9.

29. Van Dongen CAM, Geilenkirchen WLM. The development of Dentalium with special reference to the significance of the polar lobe. I, II, III. Division chronology and development of the cell pattern in Dentalium dentale (Scaphopoda). Proc Kongl Ned Akad v Wet Ser C. 1974;77:57-100.

30. Van Dongen CAM, Geilenkirchen WLM. The development of Dentalium with special reference to the significance of the polar lobe. IV. Division chronology and development of the cell pattern in Dentalium dentale after removal of the polar lobe at first cleavage. Proc Kongl Ned Akad v Wet Ser C. 1975;78:358-75.

31. Van Dongen CAM, Geilenkirchen WLM. The development of Dentalium with special reference to the significance of the polar lobe. V and VI. Differentiation of the cell pattern in lobeless embryos of Dentalium vulgare (da Costa) during late larval development. Proc Kongl Ned Akad v Wet Ser C. 1976;79:245-66.

32. Wanninger A, Haszprunar G. The development of the serotonergic and FMRF-amidergic nervous system in Antalis entalis (Mollusca, Scaphopoda). Zoomorph. 2003;122:77-85.

33. Kojima D, Terakita A, Ishikawa T, Tsukahara Y, Maeda A, Shichida Y. A novel Go-mediated phototransduction cascade in scallop visual cells. J Biol Chem. 1997:272:22979-82.

34. Ayers T, Tsukamoto H, Gühmann M, Rajan VB, Tessmar-Raible K. A Go-type opsin mediates the shadow reflex in the annelid Platynereis dumerilii. BMC Biol. 2018;16:41.

35. Gühmann M, Jia H, Randel N, Veraszto C, Bezares-Calderon L, Michiels NK, Yokoyama S, Jékely G. Spectral tuning of phototaxis by a Go-opsin in the rhabdomeric eyes of Platynereis. Curr Biol. 2015;25:2265-71.

36. Nathans J, Hogness DS. Isolation, sequence analysis, and intronexon arrangement of the gene encoding bovine rhodopsin. Cell. 1983:34:807-14.

37. Mullen E, Johnson AH, Akhtar M. The identification of Lys-216 as the retinal binding residue in bacteriorhodopsin. FEBS Lett. 1981;130:187-93.

38. Siddaramappa S, Challacombe JF, Decastro RE, Pfeiffer F, Sastre DE, Giménez MI, Paggi R, Detter JC, Davenport KW, Goodwin L, Kyrpides N, Tapia R, Pitluck S, Lucas S, Woyke T, Maupin-Furlow J. A comparative genomics perspective on the genetic content of the alkaliphilic haloarchaeon Natrialba magadii ATCC 43099T. BMC Genomics. 2012:13:165.

39. Spudich JL. The multitalented microbial sensory rhodopsins. Trends Microbiol. 2006:14:480-7.

40. Robinson PR, Cohen GB, Zhukovsky EA, Oprian DD. Constitutively active mutants of rhodopsin. Neuron. 1992:9:719-25.

41. Tessmar-Raible K, Raible F, Christodoulou F, Guy K, Rembold M, Hausen $\mathrm{H}$, Arendt D. Conserved sensory-neurosecretory cell types in annelid and fish forebrain: insights into hypothalamus evolution. Cell. 2007;129:1389-400.

42. Passamaneck YJ, Furchheim N, Hejnol A, Martindale MQ, Lüter C. Ciliary photoreceptors in the cerebral eyes of a protostome larva. EvoDevo. 2011:2:6. 
43. Meng F, Zhao Y, Postlethwait JH, Zhang C. Differentially expressed opsin genes identified in Sinocyclocheilus cavefish endemic to China. Curr Zool. 2013;59:170-4.

44. Wollesen T, Rodríguez Monje SV, de Oliveira A, Wanninger A. Staggered Hox expression is more widespread among molluscs than previously appreciated. Proc R Soc B. 2018;285:1513.

45. Larsson A. AliView: a fast and lightweight alignment viewer and editor for large data sets. Bioinformatics. 2014;30:3276-8.

46. Stamatakis A. RAxML version 8: a tool for phylogenetic analysis and postanalysis of large phylogenies. Bioinformatics. 2014;30(9):1312-3.

47. Rambaut A. FigTree v1.4.1. 2008; http://tree.bio.ed.ac.uk/figtree.
48. Yang J, Yan R, Roy A, Xu D, Poisson J, Zhang Y. The I-TASSER suite: protein structure and function prediction. Nat Methods. 2014;12:7.

49. Pettersen EF, Goddard TD, Huang CC, Couch GS, Greenblatt DM, Meng EC, Ferrin TE. UCSF chimera-a visualization system for exploratory research and analysis. J Comp Chem. 2004;25(13):1605-12.

50. Jékely G, Arendt D. Confocal detection of NBT/BCIP in situ hybridization samples by reflection microscopy. Biochemica. 2007;4:12-4.

\section{Publisher's Note}

Springer Nature remains neutral with regard to jurisdictional claims in published maps and institutional affiliations.
Ready to submit your research? Choose BMC and benefit from:

- fast, convenient online submission

- thorough peer review by experienced researchers in your field

- rapid publication on acceptance

- support for research data, including large and complex data types

- gold Open Access which fosters wider collaboration and increased citations

- maximum visibility for your research: over $100 \mathrm{M}$ website views per year

At BMC, research is always in progress.

Learn more biomedcentral.com/submissions 